\title{
Assistive technologies for self-managed pressure ulcer prevention in spinal cord injury: A scoping review
}

\author{
James Y. Tung, PhD; ${ }^{*}$ Brent Stead, PhD, MBA; ${ }^{2}$ William Mann, MBA; ${ }^{2}$ Ba' Pham, PhD; ${ }^{3}$ Milos R. Popovic, PhD ${ }^{4}$ \\ ${ }^{1}$ Department of Mechanical and Mechatronics Engineering, University of Waterloo, Waterloo, Canada; ${ }^{2}$ SensiMAT \\ Systems Inc, Toronto, Canada; ${ }^{3}$ Toronto Health Economics and Technology Assessment Collaborative, University of \\ Toronto, Toronto, Canada; ${ }^{4}$ Institute of Biomaterials and Biomedical Engineering, University of Toronto, Toronto, Can- \\ ada; and Toronto Rehabilitation Institute, University Health Network, Toronto, Canada
}

\begin{abstract}
Pressure ulcers (PUs) in individuals with spinal cord injury (SCI) present a persistent and costly problem. Continuing effort in developing new technologies that support selfmanaged care is an important prevention strategy. Specifically, the aims of this scoping review are to review the key concepts and factors related to self-managed prevention of PUs in individuals with SCI and appraise the technologies available to assist patients in self-management of PU prevention practices. There is broad consensus that sustaining long-term adherence to prevention regimens is a major concern. Recent literature highlights the interactions between behavioral and physiological risk factors. We identify four technology categories that support self-management: computer-based educational technologies demonstrated improved short-term gains in knowledge (2 studies), interface pressure mapping technologies demonstrated improved adherence to pressure-relief schedules up to 3 mo (5 studies), electrical stimulation confirmed improvements in tissue tolerance after $8 \mathrm{wk}$ of training (3 studies), and telemedicine programs demonstrated improvements in independence and reduced hospital visits over 6 mo (2 studies). Overall, self-management technologies demonstrated low-to-moderate effectiveness in addressing a subset of risk factors. However, the effectiveness of technologies in preventing PUs is limited due to a lack of incidence reporting. In light of the key findings, we recommend developing integrated technologies that address multiple risk factors.
\end{abstract}

Key words: assistive technology, integrated technologies, pressure ulcer, pressure ulcer incidence, pressure ulcer prevention, risk factors, SCI, self-managed care, spinal cord injury, wheelchairs.

\section{INTRODUCTION}

Individuals who experience a spinal cord injury (SCI) face numerous obstacles that require daily attention to mitigate complications that may arise throughout their lives [1]. One particularly devastating complication is pressure ulcers (PUs), typically resulting from partial or complete lack of control and sensation in the contact areas during sitting. This lack of sensation and mobility leads to extended periods of nonmovement that may result in excessive tissue pressures and ultimately necrosis. The unfortunate reality is that up to 95 percent of individuals with SCI may develop an advanced stage 3 or 4 PU that penetrates to adipose tissue and bone, respectively, in their lifetime [2-4]. The physical implications of PUs include infections, permanent disfigurement, and risk of death [5]. In addition to the physical symptoms, social and work activities are disrupted by prolonged

\footnotetext{
Abbreviations: $\mathrm{CCM}=$ chronic care model, $\mathrm{CPG}=$ clinical practice guideline, ES = electrical stimulation, IPM = interface pressure mapping, $\mathrm{PU}=$ pressure ulcer, $\mathrm{RCT}=$ randomized control trial, SCI = spinal cord injury.

*Address all correspondence to James Y. Tung, PhD; Department of Mechanical and Mechatronics Engineering, University of Waterloo, 200 University Ave W, Waterloo, ON N2L 3G1, Canada; 519-888-4567, ext 33445.
}

Email: james.tung@uwaterloo.ca http://dx.doi.org/10.1682/JRRD.2014.02.0064 
hospitalization or bed rest in treatment and rehabilitation of advanced PUs [6]. Furthermore, direct annual medical costs associated with treating PUs in veterans with SCI in the United States alone have been estimated at $\$ 89$ million (United States dollars) [7] and between $\$ 173$ million and \$316 million (Canadian dollars) in communitydwelling SCI individuals in Canada [8].

Considering the negative medical and economic consequences of PUs, the impetus for effective prevention strategies is clear. Clinical practice guidelines (CPGs) addressing the assessment and prevention of PUs place a high priority on a thorough skin and risk assessment and individualized care plan, including pressure relief schedules and devices, following initial injury and/or subsequent hospitalization [9]. To properly equip patients with the knowledge and tools needed for care when they return to the community, education programs are delivered to patients, family, and caregivers about key risk factors, pressure-relief strategies, and how to inspect and care for the skin [9]. Despite these practices, long-term adherence to recommended measures to prevent PUs remains suboptimal. A survey of wheelchair users with SCI living at home in the Netherlands indicated that less than 50 percent of respondents performed pressure-relief maneuvers "regularly" or "often" [10] and adherence to preventative practices tends to decay over time in community-dwelling individuals with SCI [11].

The need to support patients with complex chronic conditions to make day-to-day decisions about, or selfmanage, their illnesses can be informed by the chronic care model (CCM). Based on evidence that patientdriven behaviors or activities can reduce the likelihood of complications associated with chronic conditions, such as PUs in SCI, the CCM posits a self-management framework [12]. This framework focuses on developing a collaborative relationship between care professionals and patients to support the best possible quality of life. A central tenet of this framework is developing self-efficacy, reflected by patient confidence to carry out a behavior to achieve a goal, toward an informed patient engaged in self-management decisions about his or her day-to-day life [13]. The focus of this article is on examining the use of technology to support self-management as part of an overall PU prevention strategy.

Established technologies aimed at self-managed care to reduce the risk of developing PUs focus on reducing pressure magnitudes and/or durations, such as reminding individuals to perform scheduled pressure relief [14-15] or employing mechanisms to assist with repositioning (e.g., tilt function for powered wheelchairs) [16]. With the expanding accessibility and sophistication of computing technologies, new opportunities for technological approaches to assist persons with SCI in self-managed care are emerging. For instance, the use of mobile computing and communication technologies in healthcare (mHealth) has shown promise in supporting behavior change and self-management in the community [17-18]. By taking advantage of continuous communication via wireless networks and device portability, mobile text messaging and email systems have demonstrated positive adherence outcomes for tobacco cessation [19], weight loss [20], and blood glucose monitoring in young adults with diabetes [21]. Advances in mobile computing power and wireless connectivity to peripheral devices invite new possibilities for sensing, feedback, and control toward facilitating and sustaining effective self-managed prevention practices.

Our group of engineers and scientists has extensive experience developing assistive technologies aimed at improving participation in daily life for individuals who have experienced SCI, including technologies for assessment, rehabilitation, and self-managed care. Used to rapidly map the key concepts underpinning a research area and the main sources and types of evidence available, a scoping review to examine the available and relevant literature was conducted to inform development of new technologies aimed at supporting independent (or self-) management of PU prevention practices following SCI. Specifically, the aims of this scoping review are to (1) review the key concepts and factors related to selfmanaged prevention of PUs in individuals with SCI (section 1) and (2) examine and appraise the supporting evidence of technologies available to assist patients in self-management of PU prevention practices (section 2). Based on the findings from the review, recommendations for developing and evaluating new technologies will be discussed.

\section{METHODS}

With the aim of informing the development of new technologies to develop and sustain self-managed skin care in individuals with SCI, the scope of this article is to review (1) the factors associated with PU development to identify emerging themes related to self-management 
practices (section 1) and (2) studies examining the effectiveness of technological approaches aimed at facilitating self-managed prevention (section 2). A scoping review was conducted to rapidly map the key concepts identified in the former literature review to the technology evaluation in the latter review. Because of the scope of this review, we limit the key findings of the literature to summaries of factors and technologies potentially amenable to self-management interventions addressing SCI-specific PU risk factors. For a full systematic review of patient risk factors, see Coleman et al. [22], and for full reviews of all PU prevention interventions, see Regan et al. [23] and Reddy et al. [24].

\section{Data Sources}

Literature was searched using a query with the key words and terms relating to \{ "pressure ulcer" AND "spinal cord injury”\} AND \{ "self-management" OR "technology" $\}$ from PubMed and Web of Science databases published between 1975 and 2012. Table 1 shows the full set of terms used in the search. Because the scope of the article is to review primary prevention of incident PUs and secondary prevention of recurrence, studies addressing treatment of PUs only (e.g., surgical vs conservative treatment) were not included in the review.

\section{Study Selection}

After removing duplicates, the search yielded 1,178 titles (Figure 1). Titles and abstracts were screened by two researchers independently (authors 1 and 2) using the following inclusion criteria: (1) includes adult (age $>18 \mathrm{yr}$ ) participants with SCI and (2) directly addresses PU prevention or skin care as the primary objective.

\section{Data Extraction}

Following title and abstract screening, 94 full-text articles were downloaded for abstraction (Figure 1). Independent extraction of key findings was conducted by authors 1 and 2 using predefined data fields, including study characteristics (intervention type, design, participant characteristics, primary outcome measures, length of follow-up), key findings, and limitations.

\section{Data Synthesis}

Reviewed articles were categorized based on whether an assistive technology was evaluated. Studies examining interventions or underlying factors related to selfmanagement of PU prevention without the use of an assistive device or technology $(n=82)$ were included in section 1. Studies evaluating an assistive technology to facilitate self-managed PU prevention $(n=12)$ were reviewed in section 2 (Figure 1).

In section 1, a qualitative thematic analysis was used to summarize the key findings from the included studies. We used the conceptual framework depicting the interactions between pressure forces and tissue tolerances devised by Defloor to summarize the key physiological factors related to PU development [25]. To assist technology developers in understanding the role of contextual factors in self-management practices, we used behavioral models described by Clark et al. to summarize the lifestyle and contextual influences on PU management in daily life [26]. For section 2, focusing specifically on technologies for self-management, included studies were organized into four categories based on the technology applied: (1) education and behavioral interventions (2 studies), (2) interface pressure mapping (IPM) (5 studies), (3) electrical stimulation (ES) (3 studies), and (4) telemedicine (2 studies). The intervention type, study design, outcome measures used, and key findings are reported for each study.

Table 1.

Search strategy key words and related terms.

\begin{tabular}{lc}
\hline \multicolumn{1}{c}{ Key Word } & Related Term \\
\hline Pressure Ulcer & $\begin{array}{c}\text { Decubitus ulcer, pressure ulceration, pressure damage, skin ulcer, leg ulcer, foot ulcer, bedsore, } \\
\text { interface pressure. }\end{array}$ \\
$\begin{array}{l}\text { Spine or Spinal Cord Injury } \\
\text { Self-Management }\end{array}$ & $\begin{array}{l}\text { Paraplegia, tetraplegia, quadriplegia, spinal lesion, spinal cord compression, spinal cord damage. } \\
\text { Prevention, skin care, skin protection, pressure relief, exercise, physical activity, exercise therapy, } \\
\text { attitude, self-management, self-care, self-concept, self-efficacy, self-control, self-help, hygiene, } \\
\text { health education, health promotion. }\end{array}$ \\
Assistive technology, assistive devices, microcomputer, artificial intelligence, mobile telephone, \\
text message, electrode, man-machine interaction, telemetry, remote sensing, computer-assisted \\
therapy, feedback system.
\end{tabular}




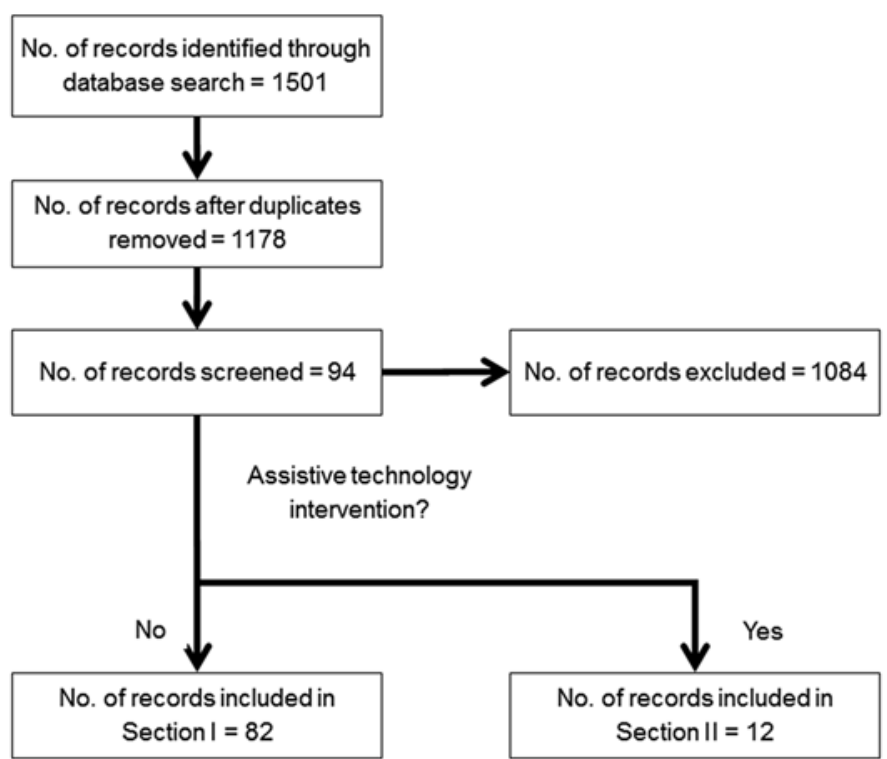

Figure 1.

Flow diagram of study selection.

To illustrate the emerging themes from the review, we employed a radar diagram to provide an overall perspective of the correspondence between knowledge of how PUs form and the technological approaches reviewed. The illustrative map comprises an octagon with each vertex representing a key risk factor. Bearing in mind that the number of factors is large, we selected a subset of the most persistent factors that relate to PU formation to display the key themes. Colored polygons are plotted to illustrate the efficacy of specific technological approaches in addressing these key factors. Starting at the center of the octagon, the vertex of each polygon was plotted according to the strength of evidence supporting the benefit of the technology. The first level (level 1) represents conceptual or theoretical benefits based on rationale or data from other sources of evidence (i.e., other chronic disease populations). Level 2 indicates anecdotal evidence (e.g., case studies) to support the technology's effectiveness in addressing the respective risk factor. Points at the third (level 3) and fourth (level 4) levels indicate evidence addressing the specific factors reported from repeated measures (i.e., within subject) and randomized control trials (RCTs), respectively. As a "bird's eye view" of the state of technological approaches, the resulting plot visually indicates the strengths and weaknesses in the current technologies to address key factors.
The ideal technology addressing all factors at the highest levels of evidence would be represented by a polygon that covers the entire plot.

\section{RESULTS}

\section{Section 1: Factors Associated with Self-Managed Prevention of Pressure Ulcers in Individuals with Spinal Cord Injury}

By definition, PU formation is a result of damage arising from loading and frictional forces, or pressure, at the interface of the individual's skin over the bony prominences and the surface with which it makes contact. However, it is recognized that the etiology of PUs is complicated and excess pressure is not the only factor leading to PU formation; tissue health, medical history, lifestyle, and psychosocial factors are identified as important contributing factors to the development of PUs [26-27].

\section{Pressure and Shear}

The scope of the present study is to summarize key factors and emerging themes associated with technology to support self-managed prevention activities (Table 2). While the etiology of PUs continues to be investigated, it is universally recognized that tissue pressure and shear are the primary causes. Laboratory, animal, and finite element modeling studies have shed light on several mechanisms by which pressure and internal strain lead to tissue breakdown, including localized ischemia, reperfusion injury, impaired lymphatic draining, and cell deformation [27]. For more detailed discussion of etiological mechanisms of PU development, refer to Bouten et al. [27] and Coleman et al. [22].

Because interface pressures are greatest around bony prominences, the highest risk of PU development is near the sacrum, coccyx, and ischial tuberosities. Animal studies in canine and swine species have demonstrated that the damaging effects of pressure are related to the local pressure magnitude and duration of exposure, indicating magnitude-duration thresholds critical to PU development (for review, see Sprigle and Sonenblum [16]). However, developing critical thresholds in humans has been difficult to establish due to wide variations in tissue tolerances [27]. Importantly, tissue necrosis can start from deep tissues as well as the surface [27], indicating the potential effect of high shear force conditions in addition to pressures at the skin-surface interface [28-29]. As a 
Table 2.

Summary of pressure ulcer (PU) development factors in individuals with spinal cord injury (SCI).

\begin{tabular}{|c|c|c|}
\hline Category & Factor & Description \\
\hline Pressure & $\begin{array}{l}\text { Support surface interface loading, deep tissue } \\
\text { strain, high shear conditions. }\end{array}$ & $\begin{array}{l}\text { Mechanical factors associated with tissue } \\
\text { damage. }\end{array}$ \\
\hline Tissue Tolerance & $\begin{array}{l}\text { Hydration, blood markers (albumin, hemoglobin), } \\
\text { age, diabetes, vascular disease (hypertension), } \\
\text { nutrition. }\end{array}$ & $\begin{array}{l}\text { Physiological factors indicative of tissue } \\
\text { tolerance to loading and recovery. }\end{array}$ \\
\hline Physical Functioning & Mobility, continence, sensation, comorbidities. & $\begin{array}{l}\text { Effects of SCI on functional capabilities } \\
\text { related to sensing high risk of PUs (e.g., pain, } \\
\text { temperature) and conducting pressure-reliev- } \\
\text { ing strategies. }\end{array}$ \\
\hline Lifestyle and Psychosocial & $\begin{array}{l}\text { Nutrition, exercise, employment, motivation, } \\
\text { situational awareness, daily care, social support, } \\
\text { work and leisure activities, psychiatric disor- } \\
\text { ders. }\end{array}$ & $\begin{array}{l}\text { Daily life factors that influence physical, } \\
\text { mental, and environmental protection } \\
\text { mechanisms. }\end{array}$ \\
\hline
\end{tabular}

high priority area for research, developing more comprehensive biomechanical models that elucidate the roles of pressure and shear force in the development of PU will contribute toward better intervention design [30].

\section{Tissue Tolerance}

In addition to the risk associated with excessive magnitude of and exposure to pressure, factors related to the ability of tissues to tolerate and recover from loading are recognized contributors [25]. Indicators of poor tissue health, such as low hydration, blood protein (i.e., albumin), and hemoglobin levels have been associated with low tissue tolerance for pressure and increased risk for PU development [22]. Similarly, history of vascular disease (e.g., diabetes, hypertension), poor nutrition, and advanced age predispose individuals to increased risk due to a higher likelihood of low tissue tolerance [22]. Conversely, individuals who engage in healthy lifestyles, such as eating well, exercising regularly, and abstaining from heavy smoking, are likely to be at higher tissue tolerance for pressure and lower risk of developing PUs [31].

\section{Functional Capabilities}

Individual capabilities, such as functional mobility, incontinence, and sensation, are valuable indicators to assess individual risk of exposure to lengthy, hig4-magnitude pressures. Within the population with SCI, significant variation exists in mobility capabilities that affect PU risk. The ability to independently shift position to relieve pressure is a significant advantage compared with dependency of an individual with SCI who relies on attendants or devices to change position [22]. For example, age- related decline in strength and/or development of shoulder pain may contribute to reduced effectiveness of pressure relief maneuvers [32]. Furthermore, a number of other factors may contribute to the risk of developing PUs by compromising the ability to identify high-risk situations (e.g., impaired sensation of pain, moisture, temperature, and/or pressure) [22].

\section{Lifestyle and Psychosocial Factors}

In addition to maintaining a healthy lifestyle (i.e., eating well and regular exercise), emerging evidence demonstrates the role of behavioral patterns in PU development. Recent qualitative studies have examined how risk of developing PUs unfolds from everyday life situations. These studies examining the sequence of events leading to the development of PUs demonstrate that unexpected events (e.g., lengthy flight delay, change in care personnel) disrupt established prevention routines [26]. Decisions in daily activities, decay in adherence to prevention behaviors, lack of situational awareness, motivation, and access to needed services and supports are among the key principles pertaining to lifestyle that could increase the risk of developing PUs [11]. For example, skipping scheduled prevention activities to attend to work is commonly reported [11].

Because consistent surveillance and preventative measures require constant attention and are time-consuming, sustaining long-term adherence to prevention programs is a critical issue. In a study conducted in the Netherlands ( $n=$ 410), 22.9 percent of wheelchair users with SCI reported they "never" do pressure relief exercises, 29.7 percent indicated "sometimes," and 26.5 percent indicated "often," 
with only 20.9 percent stating that they always performed exercises every $30 \mathrm{~min}$ [33]. Studies on monitoring seat pressures have reported evidence that community-dwelling patients with SCI in wheelchairs routinely go $60 \mathrm{~min}$ or more without performing a pressure-relieving exercise [28,34]. Furthermore, rigorous prevention regimens can interfere with leisure and work activities, which can affect an individual's relationships and quality of life $[5,11,35]$.

A common theme arising from qualitative studies is the influence of sustained motivational commitment and short-term situational awareness on adherence to preventative measures. While generalized knowledge about prevention techniques acquired during rehabilitation can lead to lasting motivational commitment for some, others may only become motivated following personal experience with a PU or in consideration of their life partners (e.g., spouses) [35]. However, long-term motivation may decay over time due to distractions, overconfidence, forgetfulness, and/or comorbid conditions (e.g., depression, fatigue) [12,33]. As an avenue to address nonadherence, Jones et al. examined the effect of introducing monetary incentives to motivate positive behavior to reduce the risk of PUs in six participants [36]. While some participants responded to monetary rewards, leading to a reduction in PU severity, fewer hospital admissions, and lower medical care costs associated with PU treatment, the study was limited by small sample size and high dropouts [36]. Importantly, the characteristics of behavioral interventions (e.g, type, frequency) to foster patient engagement in self-management remains under-examined.

In addition to long-term motivation, simultaneous awareness of situational context contributes to preventative behavior. An examination of 20 community-dwelling adults with SCI paraplegia or tetraplegia describes the development of PUs in the context of everyday situations [26]. The interaction between background risk factors (e.g., physical frailty, incontinence, lack of support) and events from daily life situations contribute to specific time windows of elevated risk [26]. Situations that divert attention from preventative measures, such as external exigencies (e.g., travel delays, work pressures), forgetfulness, activity choices, or attending to comorbidities, have also been recognized as events that contribute to increased risk of developing or exacerbating a PU [12,33,35-36].

\section{Section 2: Technologies for Self-Managed Prevention of Pressure Ulcers}

In this section of the article, literature describing and evaluating technologies aimed at advancing self-management of PU prevention in community-dwelling individuals with SCI is reviewed. Based on the studies extracted from searching the literature, we identify four categories of technology: (1) education and behavioral interventions (2 studies), (2) IPM (5 studies), (3) ES (3 studies), and (4) telemedicine (2 studies). Table 3 describes the study design, sample size and characteristics, outcome measures, and key findings of the studies reviewed. The technology intervention studies in this section of the review (total: 12 studies) included four RCTs, seven studies with repeated-measures design, and one case study. Sample sizes were generally small, with only two (of 12 total studies) trials with more than 40 subjects. Outcomes were generally limited to measures of risk factors (e.g., regional pressures), with only two studies reporting the incidence of PUs as an outcome. Follow-up duration ranged from short- (1-7 d, 7 studies) to medium- (1-12 wk, 2 studies) to long-term ( $>3$ mo, 3 studies).

\section{Educational Technologies}

Two studies of technologies focused on improving the effectiveness of education programs for PU prevention were reviewed. Typically offered during hospital and rehabilitation stays, education programs offered have shown some benefits in increasing frequency of pressurerelieving behaviors [37-38] and prolonging the time to PU recurrence, particularly in conjunction with frequent follow-up [39]. Not only do best practice guidelines recommend educating individuals with SCI on basic knowledge of risk factors and prevention practices, but also to inform family and caregivers [9]. To reduce costs and mitigate increasing demand for services, the current trend in care is shifting toward shortening both the hospital length of stay and duration of intensive rehabilitation [38]. These trends may limit the delivery of education programs within the time spent in hospital or intensive rehabilitation.

Developed to improve accessibility, e-learning software consisting of material in text, audio, images, and video media has demonstrated the ability to improve knowledge regarding PU prevention in a sample of 20 individuals with SCI [38]. Pellerito reported improved performance and efficacy of pressure-relieving techniques following a computer-based education program in 
Table 3.

Technologies to prevent pressure ulcers (PUs) in individuals with spinal cord injury (SCI).

\begin{tabular}{|c|c|c|c|c|}
\hline Study & Type of Device & Study Design & Outcomes & Results \\
\hline \multicolumn{5}{|l|}{ Educational } \\
\hline $\begin{array}{l}\text { Brace and Schubart } \\
\text { (2010) [38] }\end{array}$ & E-learning program. & $\begin{array}{l}\text { Repeated measures } \\
\text { (baseline, intervention); } \\
20 \text { patients with SCI } \\
\text { (FU: }<1 \text { d). }\end{array}$ & PU knowledge score. & $\begin{array}{l}\text { Median knowledge } \\
\text { increased from } 65 \text { to } \\
92.5 \text { (out of 100) } \\
\text { postintervention. }\end{array}$ \\
\hline Pellerito (2003) [37] & $\begin{array}{l}\text { Traditional and } \\
\text { computer-aided } \\
\text { education. }\end{array}$ & $\begin{array}{l}\text { Repeated measures } \\
\text { (baseline, standard, } \\
\text { intervention); } 3 \text { patients } \\
\text { with SCI (FU: }<1 \text { d). }\end{array}$ & $\begin{array}{l}\text { No. of pressure-relieving } \\
\text { behaviors and no. of skin } \\
\text { maintenance behaviors. }\end{array}$ & $\begin{array}{l}\text { Computer-aided education } \\
\text { is more effective in } 2 \text { of } \\
3 \text { patients in performing } \\
\text { pressure-relieving behavior; } \\
\text { computer-aided education } \\
\text { increased no. of skin } \\
\text { maintenance behaviors. }\end{array}$ \\
\hline
\end{tabular}

\section{Interface Pressure Mapping}

Chawla et al. (1979) [14] Low-density pressure map and visual/audio alarm at $10 \mathrm{~min}$ intervals to prompt push-up pressure relief.
Repeated measures (baseline, intervention, post); 10 patients with SCI (FU: 3 mo).
No. of 10 min alarms; no. of missed alarms; no. of push-ups performed; no. of push-up errors ( $<20$ s duration).

Increase in no. of alarms in post compared with baseline; no difference in mean no. of 10 min missed alarms; no difference in no. of push-ups; mean no. of cumulative push-up errors decreased in post compared with baseline.

Times to respond between tactile and audio feedback were not significantly different.

adults (FU: $<1 \mathrm{~d}$ ).

Repeated measures (baseline vs intervention); 20 patients with SCI (FU: 2 wk).

\begin{tabular}{ll} 
Merbitz et al. (1985) [48] & $\begin{array}{l}\text { Low-density pressure } \\
\text { map and timer; oral or } \\
\text { written feedback. }\end{array}$ \\
\hline Chenu et al. (2009) [47] & $\begin{array}{l}\text { High-density pressure } \\
\text { map and lingual } \\
\text { feedback }\end{array}$
\end{tabular}

\section{Repeated measures \\ (baseline vs intervention); 7 patients with SCI (FU: 32-75 d)}

RCT (No intervention vs feedback); 24 healthy young adults (FU: $<1 \mathrm{~d}$ ).
Ability of subject to reach target posture; reduction in overpressure; reduction in over-pressure in high-risk areas.
Uninterrupted sitting time; frequency of pressure-relieving behaviors.

Lift-off intervals;
compliance with
intervention.
intervention.

Feedback resulted in reduced uninterrupted sitting durations; feedback resulted in more frequent pressure-relieving behaviors.

Wide variability between and within patients over time; no significant effectiveness of timer or oral or written feedback.

Intervention group reached correct posture more frequently than controls; intervention group decreased over-pressure more than controls; pressure in high-risk areas was reduced in intervention group.

No difference in TcPO2; no difference in pressure distribution; no difference in gluteal muscle thickness. 
Table 3. (cont)

Technologies to prevent pressure ulcers (PUs) in individuals with spinal cord injury (SCI).

\begin{tabular}{|c|c|c|c|c|}
\hline Study & Type of Device & Study Design & Outcomes & Results \\
\hline $\begin{array}{l}\text { Bogie and Triolo (2003) } \\
\text { [49] }\end{array}$ & $\begin{array}{l}\text { Neuromuscular } \\
\text { ES training. }\end{array}$ & $\begin{array}{l}\text { Repeated measures } \\
\text { (baseline vs interven- } \\
\text { tion); } 8 \text { patients with } \\
\text { SCI (FU: } 8 \text { wk). }\end{array}$ & $\begin{array}{l}\text { Mean interface pressure; } \\
\text { high-risk regional } \\
\text { pressure; TcPO2. }\end{array}$ & $\begin{array}{l}\text { No significant differences } \\
\text { in mean interface pressure } \\
\text { levels; mean ischial } \\
\text { pressure uniformly decreased } \\
\text { poststimulation; baseline } \\
\text { mean unloaded tissue oxygen } \\
\text { levels increased from 1\% to } \\
36 \% \text { poststimulation. }\end{array}$ \\
\hline
\end{tabular}

$\begin{array}{lllll}\text { Bogie et al. (2006) [50] } & \begin{array}{l}\text { Neuromuscular } \\ \text { ES training. }\end{array} & \begin{array}{l}\text { Repeated measures } \\ \text { (baseline vs interven- }\end{array} & \begin{array}{l}\text { Gluteal muscle thick- } \\ \text { ness; regional interface }\end{array} & \begin{array}{l}\text { Increased muscle thickness; } \\ \text { reduced ischial pressure; }\end{array} \\ & \begin{array}{l}\text { tion); single-case study } \\ \text { in patient with SCI }\end{array} & \begin{array}{l}\text { pressures; regional } \\ \text { (FU: 7 yr). }\end{array} & \begin{array}{l}\text { blood flow; self-reported } \\ \text { sitting tolerance. }\end{array} & \text { sitting tolerance doubled. }\end{array}$

\section{Telemedicine}

Phillips et al. (1999) [52] Telemedicine program. RCT; 37 patients with SCI in 3 groups (video [12], telephone [13], standard care [10]) (FU: 6-8 mo).
No. of PUs; ER visits, hospitalizations, and doctor visits; return to work rate.
Video group reported highest number of PUs; standard care group reported lowest number of ER visits, hospitalizations, and doctor visits; $44 \%$ of video group returned to work compared with $33 \%$ and $20 \%$ of telephone and standard care groups, respectively.

\begin{tabular}{|c|c|c|c|c|}
\hline Dallolio et al. (2008) [53] & Telemedicine program. & $\begin{array}{l}\text { RCT; } 127 \text { patients } \\
\text { with SCI in } 2 \text { groups } \\
\text { (telemedicine [62], } \\
\text { standard care [65]) } \\
\text { (FU: } 6 \text { mo). }\end{array}$ & FIM; PU incidence rates. & $\begin{array}{l}\text { Increased mean total FIM } \\
\text { scores; no group differences } \\
\text { in PU incidence rate. }\end{array}$ \\
\hline
\end{tabular}

three individuals with SCI [37]. Furthermore, computeraided programs may promote higher engagement in the learning process from self-instruction at the learner's individual rate (i.e., when he or she is ready) and with privacy in the learning environment [37]. Conversely, remote education programs lack return demonstration of skill, professional feedback on critical pressure-relief techniques, and extrinsic motivation to learn, which may limit the effectiveness of such programs. Due to small sample sizes from the two included studies (total: 23 participants) and short-term follow-up durations (1-5 d), the supporting evidence for the long-term effects of these interventions is limited.

\section{Interface Pressure Mapping}

Five studies focused on evaluating the effectiveness of IPM technology on self-managed prevention of PUs were reviewed. For the prevention of PUs in individuals with SCI, CPGs recommend full-body inspection of the skin, risk assessment using standardized instruments (e.g., Braden Scale; for review, see Mortenson et al. [40]), and inspection of support surfaces for their capacity to reduce interface pressure, friction, and shear [9]. IPM that directly measures skin-surface pressures has been widely studied and is recognized as one type of technology to identify unacceptably high pressures for support surface assessment [16]. In particular, IPM has been demonstrated to provide valid measurements in assessing the effectiveness of pressure relief strategies, such as weight-shifts and repositioning, or to evaluate pressure-redistribution cushioning [41]. While the use of IPM technology to visualize pressure is increasing in wheelchair and seating clinics [42], consensus regarding quantitative real- or near real-time analysis of interface 
pressure measurement continues to be an active research topic [43].

Based on institutionalized populations, recommended pressure-relief interventions include weight-shifting or repositioning at least every $60 \mathrm{~min}$ and avoiding prolonged sitting durations ( $>2 \mathrm{~h}$ ) [9]. While evidence to inform schedule guidelines is lacking in the community-dwelling population, CPGs recommend pressure relief to be performed every 15 to $30 \mathrm{~min}$ for 30 to $120 \mathrm{~s}$ [44]. Targeting wheelchair users with SCI who do not "always" perform pressure relief, estimated to be 79.1 percent of patients in the Netherlands [33], IPM has the potential to monitor interface pressure and prompt users to adhere to pressurerelief schedules or alert in high-risk situations. Furthermore, manufacturing improvements have significantly reduced the cost of IPM technology. The short-term effects of IPM technologies provide some evidence of increased compliance with pressure-relief schedules [45-47], whereas other studies had mixed or no effect $[14,48]$. However, it is also noted that decay in adherence with performing weight-relieving exercises may persist even when these alerting devices are used $[14,48]$. To address nonadherence to alerts, two included studies evaluated the relative benefits of different feedback modalities (e.g., audio vs tactile [45]). While both studies found no significant difference in response rate or reaction time, these studies were limited to healthy adults. Individual functional capabilities, such as residual sensory impairment, are recognized factors to be considered in the evaluation of the comparative effectiveness of these specific modalities [47].

\section{Electrical Stimulation}

Three studies evaluating the application of neuromuscular ES of paralyzed gluteal muscles to produce pressure relief and reduce the risk of PUs were reviewed. In a repeated-measures study of eight individuals with SCI, Bogie and Triolo found that an 8 wk conditioning program using external stimulation can produce changes in ischial pressures and promote blood flow to increase tissue tolerance [49]. In a single-case study $(n=1)$, longterm ES produced numerous positive effects, including increased muscle mass and blood flow, reduced ischial pressures, more effective weight-shifting, and longer sitting tolerance durations [50]. However, a study examining the potential of lower threshold sensory stimulation did not produce positive effects, suggesting that motor stimulation affecting contractile muscle response is critical [51]. While these results are promising, they are lim- ited by small samples sizes (total $n=9$ ) and are invasive because ES requires surgical implantation of stimulation electrodes.

\section{Telemedicine}

Two studies reporting the effects of telemedicine interventions, specifically the use of video conferencing technology, were reviewed. Telemedicine technology may help address the gap in professional care and reduce complications following discharge from the inpatient SCI unit to the community. By improving the continuity of care, telemedicine has the potential to assist in reducing isolation of patients and caregivers, support those who live long distances from SCI units, and promote self-management through education and motivation. Phillips et al. examined the effectiveness of weekly counseling sessions delivered remotely through telemedicine on the number of PUs, hospital and physician visits, and return to work rate [52]. Unexpectedly, the telemedicine group reported the highest number of PUs compared with control groups receiving telephone care or no extra care. This may be partially attributed to superior identification of less serious stage 1 and 2 PUs by nurses using telemedicine (i.e., video) inspection compared with self-reporting by the telephone and control groups [52]. In a larger study comparing the effects of telemedicine to usual care, Dallolio et al. found no differences in PU outcomes at the 2 and 6 mo periods [53]. However, both studies found substantial improvements on independence measures (e.g., return to work rates [52] and Functional Independence Measure [53]), which are protective factors of PU risk.

\section{Correspondence Between Risk Factors and Technological Approaches}

To graphically illustrate the findings from the review, we employ a radar diagram (Figure 2) to provide an overall perspective of the correspondence between knowledge of factors related to PU formation (section 1) and the technological approaches to assist with self-management (section 2). Based on the findings from the review of factors related to PU formation, we selected eight persistent factors for the vertices of the radar diagram: pressure monitoring, tissue blood flow, muscle mass, pressurerelief (e.g., weight-shifts), access to support, knowledge, situational awareness, and adherence to regimens. Colored polygons were plotted to represent the coverage of four technological approaches reviewed to address these key factors in reducing the risk of developing PUs. 


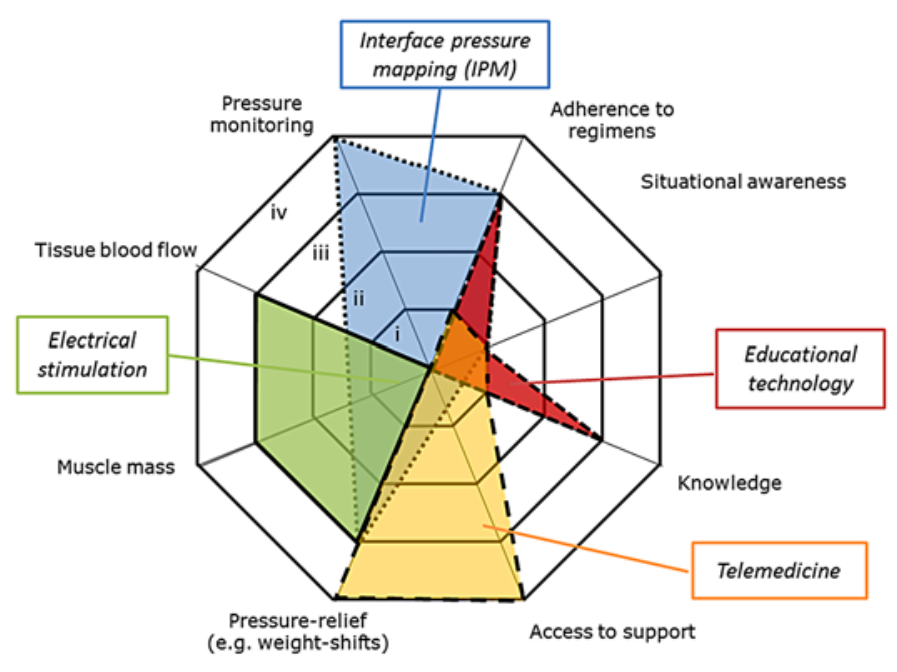

Figure 2.

Radar plot visually indicating strengths and weaknesses in current technological approaches. Axes of octagon represent key identified factors influencing pressure ulcer risk: interface pressure mapping (IPM), tissue blood flow, muscle mass, pressure-relief (e.g., weight-shifts), access to support, knowledge, situational awareness, and adherence to regimens. Reviewed technological approaches are represented by colored polygons: IPM, electrical stimulation, educational technology, and telemedicine. Vertex of each polygon is plotted according to strength of evidence supporting benefit of technology (level 1: conceptual or theoretical benefits, 2: anecdotal and/or case studies, 3: repeated-measures and/or time-series studies, 4: case-control and/or randomized control trials).

Overall, no single technology demonstrated effectiveness in addressing more than 50 percent of the factors in the radar plot. Targeting five of eight identified factors, telemedicine (Figure 2, yellow polygon) has the greatest potential to cover the most area in a single technology. Telemedicine demonstrated improved access to support and improved functional capabilities, such as transfers and execution of pressure-relief behaviors, in higher quality studies (level 4). However, the evidence of telemedicine technology to address adherence, awareness, knowledge, and consistent execution remains at the conceptual or anecdotal level (level 1).

IPM (Figure 2, blue) demonstrated effectiveness in addressing three factors: pressure monitoring (level 4), adherence to regimens (level 3), and improved ability to execute pressure-relief behaviors (level 2). Conceptually, IPM monitoring can assist with raising awareness of high-risk situations (level 1), but the evidence remains to be demonstrated.

Educational technology (Figure 2, red) facilitates adherence to regimens (level 3) and increases knowledge of factors related to PU development (level 3). Similar to IPM and telemedicine approaches, educational technology has been suggested to increase situational awareness capabilities with only limited anecdotal or theoretical evidence (level 1).

ES (Figure 2, green) was the only technology that addressed factors related to increasing tissue tolerance, such as tissue blood flow (level 3) and muscle mass (level 3). Moderate evidence supported the effectiveness of ES approaches to improve the execution of pressure relief (level 3).

\section{DISCUSSION}

PUs in community-dwelling individuals with SCI present a persistent and costly problem in patient physical symptoms and the associated economic effect to manage treatment. This article reviewed the factors and technological approaches related to self-managed prevention of PUs to guide future development of assistive devices. In reviewing the factors related to self-management (section 1), a key finding was the growing understanding of the interaction between physiological, lifestyle, and psychosocial factors that contribute to the breakdown of regimens and elevated risk for PUs. The review of technologies for self-management (section 2) indicated the potential for IPM, telemedicine, and ES approaches to address a subset of mediating risk factors. However, no direct evidence supported their effectiveness in reducing the incidence of PUs. When comparing the knowledge regarding PU risks (section 1) and the evidence regarding the effectiveness of the reviewed technologies to assist in self-management (section 2), we illustrate the potential for integrated approaches to address multiple risk factors in a radar diagram.

While the evidence linking physiological factors related to the risk of developing PUs continues to grow [22], emerging knowledge regarding behavioral and contextual factors may be more relevant in guiding the development of technological interventions for selfmanagement. As indicated in the CCM, the need for persistent surveillance and preventative measures requires constant attention, consumes time, and reflects 
the critical role that sustaining motivation and awareness of high-risk situations can play in daily care. With the potential to reach beyond the clinic and to the community, we recommend that future research should examine developing or integrating monitoring technologies to promote situational awareness and adherence. Recent observational studies highlight the influence of time events on PU formation, particularly in situations that shift attention away from usual prevention routines and/or pose unique threats (e.g., change in attendant care, unexpected travel delays, and folds in clothing) [26]. By intelligently providing information of the contextual factors that contribute to risk, similar to mobile computing and communication technologies in healthcare approaches to support self-management for other chronic conditions [17-18], assistive technologies may help alleviate the burden of constant surveillance.

IPM technology is a promising approach to monitor and provide real-time feedback to individuals with SCI regarding high-risk situations. The review of IPM studies demonstrated moderate effectiveness in adhering to schedules resulting in reduced uninterrupted sitting durations and increased frequency of pressure-relief behavior $[14,46,48]$. However, these studies based on maintaining time-based schedules also noted decay in adherence over time $[14,48]$. Future IPM approaches may consider the utility of providing more detailed feedback regarding highrisk situations, such as abnormally high local pressure due to a fold in clothing or long accumulation of uninterrupted pressures due to travel delays, to better inform users of the situations that pose a high risk in real-time.

While the technological approaches reviewed have demonstrated moderate success in addressing mitigating factors (e.g., lack of knowledge), the effectiveness in preventing PUs as a primary outcome is very limited. For example, ES has demonstrated moderate evidence to improve tissue tolerance to interface pressures $[42,46]$ and telemedicine improved functional independence [4445]. Despite these improvements, a lack of incidence data exists to directly support the effectiveness of technological approaches in preventing PUs. Only one study (of the 12 reviewed in section 2) provided PU incidence as an outcome [53], likely due to pragmatic limitations in recruiting sufficiently large samples (2 studies with $n \geq$ 40) and long-term follow-up data (3 studies with followup $\geq 3 \mathrm{mo}$ ). Importantly, this lack of direct PU incidence data seriously limits the ability to evaluate the effectiveness of technologies to support evidence-based clinical use. Furthermore, the scope of reviewed technological approaches is limited to a subset of the multiple factors contributing to risk. To our best knowledge, no technology-based studies meeting the inclusion criteria address other pertinent factors contributing to PU risk (e.g., moisture, nutrition).

Based on the emerging themes of our literature review, illustrated through the radar plot, we recommend that new technologies integrate current knowledge in a multifactorial approach. Recognizing that the formation of PUs often results from the interaction of multiple factors suggests that an ideal prevention strategy would be to address all of the key identified risks. Pragmatically, multifactorial approaches have been demonstrated to be effective in managing other chronic conditions with complex interactions, such as fall prevention [54], diabetes [55], heart failure [56], and Parkinson disease [57]. However, the reviewed technological approaches are limited to a subset of risk factors, as illustrated in the radar diagram. We argue that new designs for assistive technology to support PU prevention should incorporate multiple approaches to reduce the burden associated with the perpetual threat of PUs for individuals with SCI.

For instance, monitoring pressure may be a useful means to enhance situational awareness by inferring contextual factors (e.g., activity type and duration) in addition to monitoring adherence to pressure-relief schedules. Commercially available sensors may be used to capture contextual information (e.g., physical location, ambient temperature) to identify situations with higher risks. In the current climate of pervasive mobile technology with successful implementation to deliver behavior change interventions (e.g., weight loss, smoking cessation, and diabetes management [17]), strong opportunities exist to integrate approaches using mobile device platforms.

This review highlights some methodological limitations of the research literature. The vast majority of published studies employ the repeated-measures, or timeseries, design to evaluate the effectiveness of interventions, likely due to the limitations in recruiting sufficiently large sample sizes for RCTs. While repeated-measures studies are useful to infer statistical significance under such limitations, the potential for bias exists due to order effects. Experimental designs that counter-balance treatment order are recommended in future studies to mitigate these potential confounds. As the primary outcome, the lack of epidemiological data on PU incidence over the lifetime of individuals with SCI remains a limiting factor 
in the field [58]. In view of these difficulties, this review highlights opportunities to develop the use of technologymediated behavioral outcome measures, such as monitoring pressure relief behavior via IPM, estimating physical activity using accelerometry, and location monitoring to estimate participation, to facilitate longer-term evaluation studies.

\section{CONCLUSIONS}

Given the persistent problem of PUs following SCI, there exists a role for technology to complement current programs in developing and promoting self-managed prevention practices in the community. In reviewing the current literature, this article recognizes an emerging view that PU formation often results from the interaction of behavioral and physiological factors. A particular concern is the difficulty in sustaining long-term adherence to prevention regimens, particularly under stressful or attention-demanding circumstances. While the technologies reviewed here have demonstrated moderate effectiveness in addressing a subset of mediating factors, we recommend developing technologies to support multifactorial approaches similar to strategies for the prevention and management of other chronic conditions. In particular, integrating monitoring, support, and feedback technologies are recommended to promote situational awareness, adherence, and access to professional resources.

\section{ACKNOWLEDGMENTS}

\author{
Author Contributions: \\ Study concept and design: J. Y. Tung, B. Stead, W. Mann, \\ M. R. Popovic. \\ Acquisition, analysis, and interpretation of data: J. Y. Tung, B. Stead. \\ Drafting of manuscript: J. Y. Tung, B. Stead. \\ Critical revision of manuscript for important intellectual content: \\ J. Y. Tung, B. Stead, W. Mann, B. Pham, M. R. Popovic.
}

Financial Disclosures: Dr. Tung received compensation from SensiMAT Systems Inc (Woodbridge, Ontario, Canada) for writing the manuscript. Dr. Stead and Mr. Mann hold financial interests in SensiMAT Systems Inc. Dr. Popovic holds financial interest in MyndTec Inc (Mississauga, Ontario, Canada).

Funding/Support: This material was unfunded at the time of manuscript preparation.

\section{REFERENCES}

1. Krause JS, Saunders LL. Health, secondary conditions, and life expectancy after spinal cord injury. Arch Phys Med Rehabil. 2011;92(11):1770-75. [PMID:22032212] http://dx.doi.org/10.1016/j.apmr.2011.05.024

2. Garber SL, Rintala DH, Hart KA, Fuhrer MJ. Pressure ulcer risk in spinal cord injury: Predictors of ulcer status over 3 years. Arch Phys Med Rehabil. 2000;81(4):465-71. [PMID:10768537]

http://dx.doi.org/10.1053/mr.2000.3889

3. Fuhrer MJ, Garber SL, Rintala DH, Clearman R, Hart KA. Pressure ulcers in community-resident persons with spinal cord injury: Prevalence and risk factors. Arch Phys Med Rehabil. 1993;74(11):1172-77. [PMID:8239957]

4. Sumiya T, Kawamura K, Tokuhiro A, Takechi H, Ogata H. A survey of wheelchair use by paraplegic individuals in Japan. Part 2: Prevalence of pressure sores. Spinal Cord. 1997; 35(9):595-98. [PMID:9300964] http://dx.doi.org/10.1038/sj.sc.3100466

5. Allman RM. Pressure ulcer prevalence, incidence, risk factors, and impact. Clin Geriatr Med. 1997;13(3):421-36. [PMID:9227937]

6. Langemo DK, Melland H, Hanson D, Olson B, Hunter S. The lived experience of having a pressure ulcer: A qualitative analysis. Adv Skin Wound Care. 2000;13(5):225-35. [PMID:11075022]

7. Stroupe K, Manheim L. Cost of treating pressure ulcers for veterans with spinal cord injury. Top Spinal Cord Inj Rehabil. 2011;16(4):62-73.

http://dx.doi.org/10.1310/sci1604-62

8. Chan BC, Nanwa N, Mittmann N, Bryant D, Coyte PC, Houghton PE. The average cost of pressure ulcer management in a community dwelling spinal cord injury population. Int Wound J. 2013;10(4):431-40. [PMID:22715990] http://dx.doi.org/10.1111/j.1742-481X.2012.01002.x

9. Keast DH, Parslow N, Houghton PE, Norton L, Fraser C. Best practice recommendations for the prevention and treatment of pressure ulcers: Update 2006. Adv Skin Wound Care. 2007;20(8):447-60, quiz 461-62. [PMID:17762312] http://dx.doi.org/10.1097/01.ASW.0000284922.69932.c5

10. van Loo MA, Post MW, Bloemen JH, van Asbeck FW. Care needs of persons with long-term spinal cord injury living at home in the Netherlands. Spinal Cord. 2010; 48(5):423-28. [PMID:19884896]

http://dx.doi.org/10.1038/sc.2009.142

11. Jackson J, Carlson M, Rubayi S, Scott MD, Atkins MS, Blanche EI, Saunders-Newton C, Mielke S, Wolfe MK, Clark FA. Qualitative study of principles pertaining to lifestyle and pressure ulcer risk in adults with spinal cord injury. Disabil Rehabil. 2010;32(7):567-78. 


\section{[PMID:20136475]}

http://dx.doi.org/10.3109/09638280903183829

12. Wagner EH, Austin BT, Davis C, Hindmarsh M, Schaefer J, Bonomi A. Improving chronic illness care: Translating evidence into action. Health Aff (Millwood). 2001;20(6): 64-78. [PMID:11816692] http://dx.doi.org/10.1377/hlthaff.20.6.64

13. Bodenheimer T, Lorig K, Holman H, Grumbach K. Patient self-management of chronic disease in primary care. JAMA. 2002;288(19):2469-75. [PMID:12435261] http://dx.doi.org/10.1001/jama.288.19.2469

14. Chawla JC, Andrews B, Bar C. Using warning devices to improve pressure-relief training. Paraplegia. 1979;16(4): 413-19. [PMID:431972] http://dx.doi.org/10.1038/sc.1978.75

15. Roemer R, Lee H, Meisel H. Warning device for the prevention of ischaemic ulcers in quadriplegics. Med Biol Eng. 1976;14(5):580-81. [PMID:979385] http://dx.doi.org/10.1007/BF02478060

16. Sprigle S, Sonenblum S. Assessing evidence supporting redistribution of pressure for pressure ulcer prevention: A review. J Rehabil Res Dev. 2011;48(3):203-13.

[PMID:21480095]

http://dx.doi.org/10.1682/JRRD.2010.05.0102

17. Cole-Lewis H, Kershaw T. Text messaging as a tool for behavior change in disease prevention and management. Epidemiol Rev. 2010;32(1):56-69. [PMID:20354039] http://dx.doi.org/10.1093/epirev/mxq004

18. Fjeldsoe BS, Marshall AL, Miller YD. Behavior change interventions delivered by mobile telephone short-message service. Am J Prev Med. 2009;36(2):165-73.

[PMID:19135907]

http://dx.doi.org/10.1016/j.amepre.2008.09.040

19. Free C, Knight R, Robertson S, Whittaker R, Edwards P, Zhou W, Rodgers A, Cairns J, Kenward MG, Roberts I. Smoking cessation support delivered via mobile phone text messaging (txt2stop): A single-blind, randomised trial. Lancet. 2011;378(9785):49-55. [PMID:21722952] http://dx.doi.org/10.1016/S0140-6736(11)60701-0

20. Burke LE, Styn MA, Sereika SM, Conroy MB, Ye L, Glanz $\mathrm{K}$, Sevick MA, Ewing LJ. Using mHealth technology to enhance self-monitoring for weight loss: A randomized trial. Am J Prev Med. 2012;43(1):20-26.

[PMID:22704741]

http://dx.doi.org/10.1016/j.amepre.2012.03.016

21. Hanauer DA, Wentzell K, Laffel N, Laffel LM. Computerized Automated Reminder Diabetes System (CARDS): Email and SMS cell phone text messaging reminders to support diabetes management. Diabetes Technol Ther. 2009; 11(2):99-106. [PMID:19848576]

http://dx.doi.org/10.1089/dia.2008.0022

22. Coleman S, Gorecki C, Nelson EA, Closs SJ, Defloor T, Halfens R, Farrin A, Brown J, Schoonhoven L, Nixon J.
Patient risk factors for pressure ulcer development: Systematic review. Int J Nurs Stud. 2013;50(7):974-1003.

[PMID:23375662]

http://dx.doi.org/10.1016/j.ijnurstu.2012.11.019

23. Regan MA, Teasell RW, Wolfe DL, Keast D, Mortenson WB, Aubut JA; Spinal Cord Injury Rehabilitation Evidence Research Team. A systematic review of therapeutic interventions for pressure ulcers after spinal cord injury. Arch Phys Med Rehabil. 2009;90(2):213-31. [PMID:19236976] http://dx.doi.org/10.1016/j.apmr.2008.08.212

24. Reddy M, Gill SS, Rochon PA. Preventing pressure ulcers: A systematic review. JAMA. 2006;296(8):974-84. [PMID:16926357] http://dx.doi.org/10.1001/jama.296.8.974

25. Defloor T. The risk of pressure sores: A conceptual scheme. J Clin Nurs. 1999;8(2):206-16. [PMID:10401354] http://dx.doi.org/10.1046/j.1365-2702.1999.00254.x

26. Clark FA, Jackson JM, Scott MD, Carlson ME, Atkins MS, Uhles-Tanaka D, Rubayi S. Data-based models of how pressure ulcers develop in daily-living contexts of adults with spinal cord injury. Arch Phys Med Rehabil. 2006; 87(11):1516-25. [PMID:17084129] http://dx.doi.org/10.1016/j.apmr.2006.08.329

27. Bouten CV, Oomens CW, Baaijens FP, Bader DL. The etiology of pressure ulcers: Skin deep or muscle bound? Arch Phys Med Rehabil. 2003;84(4):616-19. [PMID:12690603] http://dx.doi.org/10.1053/apmr.2003.50038

28. Linder-Ganz E, Yarnitzky G, Yizhar Z, Siev-Ner I, Gefen A. Real-time finite element monitoring of sub-dermal tissue stresses in individuals with spinal cord injury: Toward prevention of pressure ulcers. Ann Biomed Eng. 2009; 37(2):387-400. [PMID:19034666] http://dx.doi.org/10.1007/s10439-008-9607-8

29. Linder-Ganz E, Shabshin N, Itzchak Y, Yizhar Z, Siev-Ner I, Gefen A. Strains and stresses in sub-dermal tissues of the buttocks are greater in paraplegics than in healthy during sitting. J Biomech. 2008;41(3):567-80. [PMID:18054024] http://dx.doi.org/10.1016/j.jbiomech.2007.10.011

30. Henzel MK, Bogie KM, Guihan M, Ho CH. Pressure ulcer management and research priorities for patients with spinal cord injury: Consensus opinion from SCI QUERI Expert Panel on Pressure Ulcer Research Implementation. J Rehabil Res Dev. 2011;48(3):xi-Xxxii. [PMID:21480093] http://dx.doi.org/10.1682/JRRD.2011.01.0011

31. Krause JS, Broderick L. Patterns of recurrent pressure ulcers after spinal cord injury: Identification of risk and protective factors 5 or more years after onset. Arch Phys Med Rehabil. 2004;85(8):1257-64. [PMID:15295750] http://dx.doi.org/10.1016/j.apmr.2003.08.108

32. Subbarao JV, Klopfstein J, Turpin R. Prevalence and impact of wrist and shoulder pain in patients with spinal cord injury. J Spinal Cord Med. 1995;18(1):9-13.

[PMID:7640974] 
33. Bloemen-Vrencken JH, de Witte LP, Post MW, van den Heuvel WJ. Health behaviour of persons with spinal cord injury. Spinal Cord. 2007;45(3):243-49. [PMID:16969357] http://dx.doi.org/10.1038/sj.sc.3101967

34. Bain DS, Ferguson-Pell M. Remote monitoring of sitting behavior of people with spinal cord injury. J Rehabil Res Dev. 2002;39(4):513-20. [PMID:17638148]

35. King RB, Porter SL, Vertiz KB. Preventive skin care beliefs of people with spinal cord injury. Rehabil Nurs. 2008;33(4):154-62. [PMID:18686908] http://dx.doi.org/10.1002/j.2048-7940.2008.tb00221.x

36. Jones ML, Mathewson CS, Adkins VK, Ayllon T. Use of behavioral contingencies to promote prevention of recurrent pressure ulcers. Arch Phys Med Rehabil. 2003;84(6): 796-802. [PMID:12808529] http://dx.doi.org/10.1016/S0003-9993(02)04943-2

37. Pellerito JM Jr. The effects of traditional and computeraided instruction on promoting independent skin care in adults with paraplegia. Occup Ther Int. 2003;10(1):1-19. [PMID:12830316] http://dx.doi.org/10.1002/oti.174

38. Brace JA, Schubart JR. A prospective evaluation of a pressure ulcer prevention and management E-learning program for adults with spinal cord injury. Ostomy Wound Manage. 2010;56(8):40-50. [PMID:20729562]

39. Rintala DH, Garber SL, Friedman JD, Holmes SA. Preventing recurrent pressure ulcers in veterans with spinal cord injury: Impact of a structured education and follow-up intervention. Arch Phys Med Rehabil. 2008;89(8):1429-41. [PMID:18674978] http://dx.doi.org/10.1016/j.apmr.2008.01.015

40. Mortenson WB, Miller WC; SCIRE Research Team. A review of scales for assessing the risk of developing a pressure ulcer in individuals with SCI. Spinal Cord. 2008;46(3): 168-75. [PMID:17909557] http://dx.doi.org/10.1038/sj.sc.3102129

41. Pipkin L, Sprigle S. Effect of model design, cushion construction, and interface pressure mats on interface pressure and immersion. J Rehabil Res Dev. 2008;45(6):875-82. [PMID:19009473] http://dx.doi.org/10.1682/JRRD.2007.06.0089

42. Crawford SA, Strain B, Gregg B, Walsh DM, PorterArmstrong AP. An investigation of the impact of the Force Sensing Array pressure mapping system on the clinical judgement of occupational therapists. Clin Rehabil. 2005;19(2): 224-31. [PMID:15759539] http://dx.doi.org/10.1191/0269215505cr826oa

43. Bogie K, Wang X, Fei B, Sun J. New technique for realtime interface pressure analysis: Getting more out of large image data sets. J Rehabil Res Dev. 2008;45(4):523-35. [PMID:18712638] http://dx.doi.org/10.1682/JRRD.2007.03.0046
44. Ho CH, Bogie K. The prevention and treatment of pressure ulcers. Phys Med Rehabil Clin N Am. 2007;18(2):235-53. [PMID:17543771] http://dx.doi.org/10.1016/j.pmr.2007.02.004

45. Verbunt M, Bartneck C. Sensing senses: Tactile feedback for the prevention of decubitus ulcers. Appl Psychophysiol Biofeedback. 2010;35(3):243-50. [PMID:19949852] http://dx.doi.org/10.1007/s10484-009-9124-z

46. Yang YS, Chou YC, Hsu JJ, Chang JJ. Effects of audio feedback on sitting behaviors of community-dwelling manual wheelchair users with spinal cord injuries. Assist Technol. 2010;22(2):79-86. [PMID:20698426] http://dx.doi.org/10.1080/10400435.2010.483644

47. Chenu O, Vuillerme N, Demongeot J, Payan Y. A wireless lingual feedback device to reduce overpressures in seated posture: A feasibility study. PLoS ONE. 2009;4(10):e7550. [PMID:19888336]

http://dx.doi.org/10.1371/journal.pone.0007550

48. Merbitz CT, King RB, Bleiberg J, Grip JC. Wheelchair push-ups: Measuring pressure relief frequency. Arch Phys Med Rehabil. 1985;66(7):433-38. [PMID:4015355]

49. Bogie KM, Triolo RJ. Effects of regular use of neuromuscular electrical stimulation on tissue health. J Rehabil Res Dev. 2003;40(6):469-75. [PMID:15077659] http://dx.doi.org/10.1682/JRRD.2003.11.0469

50. Bogie KM, Wang X, Triolo RJ. Long-term prevention of pressure ulcers in high-risk patients: A single case study of the use of gluteal neuromuscular electric stimulation. Arch Phys Med Rehabil. 2006;87(4):585-91. [PMID:16571402] http://dx.doi.org/10.1016/j.apmr.2005.11.020

51. Kim J, Ho CH, Wang X, Bogie K. The use of sensory electrical stimulation for pressure ulcer prevention. Physiother Theory Pract. 2010;26(8):528-36. [PMID:20649492] http://dx.doi.org/10.3109/09593981003587037

52. Phillips VL, Temkin A, Vesmarovich S, Burns R, Idleman L. Using telehealth interventions to prevent pressure ulcers in newly injured spinal cord injury patients post-discharge. Results from a pilot study. Int J Technol Assess Health Care. 1999;15(4):749-55. [PMID:10645116]

53. Dallolio L, Menarini M, China S, Ventura M, Stainthorpe A, Soopramanien A, Rucci P, Fantini MP; THRIVE Project. Functional and clinical outcomes of telemedicine in patients with spinal cord injury. Arch Phys Med Rehabil. 2008;89(12):2332-41. [PMID:19061746] http://dx.doi.org/10.1016/j.apmr.2008.06.012

54. Gillespie LD, Robertson MC, Gillespie WJ, Lamb SE, Gates S, Cumming RG, Rowe BH. Interventions for preventing falls in older people living in the community. Cochrane Database Syst Rev. 2009;(2):CD007146. [PMID:19370674]

55. Rothman RL, DeWalt DA, Malone R, Bryant B, Shintani A, Crigler B, Weinberger M, Pignone M. Influence of patient literacy on the effectiveness of a primary care-based 
TUNG et al. Technology review for pressure ulcer prevention in SCI

diabetes disease management program. JAMA. 2004; 292(14):1711-16. [PMID:15479936]

http://dx.doi.org/10.1001/jama.292.14.1711

56. Wijeysundera HC, Austin PC, Wang X, Bennell MC, Abrahamyan L, Ko DT, Tu JV, Krahn M. The effect of multidisciplinary heart failure clinic characteristics on 1-year postdischarge health care costs: A population-based study. Med Care. 2014;52(3):272-79. [PMID:24509362] http://dx.doi.org/10.1097/MLR.0000000000000071

57. van der Marck MA, Munneke M, Mulleners W, Hoogerwaard EM, Borm GF, Overeem S, Bloem BR; IMPACT Study Group. Integrated multidisciplinary care in Parkinson's disease: A non-randomised, controlled trial (IMPACT). Lancet Neurol. 2013;12(10):947-56. [PMID:23988337] http://dx.doi.org/10.1016/S1474-4422(13)70196-0

58. Chen Y, Devivo MJ, Jackson AB. Pressure ulcer prevalence in people with spinal cord injury: Age-period-duration effects. Arch Phys Med Rehabil. 2005;86(6):1208-13.
[PMID:15954061]

http://dx.doi.org/10.1016/j.apmr.2004.12.023

Submitted for publication February 28, 2014. Accepted in revised form January 26, 2015.

This article and any supplementary material should be cited as follows:

Tung JY, Stead B, Mann W, Pham B, Popovic MR. Assistive technologies for self-managed pressure ulcer prevention in spinal cord injury: A scoping review. J Rehabil Res Dev. 2015;52(2):131-46.

http://dx.doi.org/10.1682/JRRD.2014.02.0064

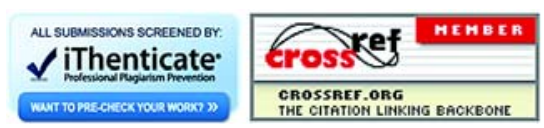


